\title{
Unusual manifestations of arrhythmogenic right ventricular dysplasia as ventricular fibrillation, atrial paralysis, and hypoexcitable right ventricle
}

\author{
BERNARD BELHASSEN, * ITZHAK SHAPIRA, * CHAIM HAMMERMAN† \\ From the Departments of Cardiology, ${ }^{\star}$ Tel-Aviv Medical Center, Tel-Aviv and $\nmid$ Rambam Medical Center, \\ Haifa, and Sackler School of Medicine, Tel-Aviv University, Israel
}

SUMMARY Ventricular fibrillation occurred in an apparently healthy 19 year old man. The results of non-invasive and invasive studies suggested right ventricular dysplasia. Electrophysiological studies showed atrial paralysis, hypoexcitability of multiple areas of the right ventricle, and inducible poorly tolerated ventricular tachycardia.

\begin{abstract}
Arrhythmogenic right ventricular dysplasia is an unusual disease in which a predominantly rightsided cardiomyopathy is associated with ventricular arrhythmias. ${ }^{1}$ Ventricular tachycardia is most commonly observed and often leads to the detection of the cardiomyopathy. We describe an apparently healthy young man who had three unusual manifestations of this disease: ventricular fibrillation as the presenting symptom, atrial paralysis, and hypoexcitable right ventricle.
\end{abstract}

\section{Case report}

A 19 year old man was referred to our hospital on 25 March 1985 for electrophysiological evaluation. His medical history had been unremarkable until 23 February 1985 when he was admitted to Rambam Medical Center with chest discomfort. A few minutes after his arrival he suddenly collapsed and was found to be in ventricular fibrillation which required several DC shocks for termination. There was no history of familial cardiomyopathy, cardiac arrhythmia, or sudden death. Physical examination did not show any abnormalities. Repeated electrocardiograms showed an atrioventricular junctional escape rhythm at a rate ranging from 39 to 48 beats/minute with an incomplete right bundle branch block pattern and a left axis deviation; poor

Requests for reprints to Dr Bernard Belhassen, Department of Cardiology, Ichilov Hospital, Tel-Aviv Medical Center, Tel-Aviv 64239, Israel.
$\mathbf{R}$ wave progression was noted in the precordial leads and there were negative $T$ waves in the anterior and lateral leads. No atrial activity could be seen. Chest $x$ rays showed cardiomegaly (cardiothoracic ratio of 0.57 ) without signs of pulmonary congestion. $M$ mode and cross sectional echocardiograms showed diffuse enlargement and hypokinesia of the right ventricle. The right atrium was also considerably dilated with a normally positioned tricuspid valve. The size of the left atrium was normal. The ejection fractions of the right and left ventricle, as determined by radionuclide ventriculography, were $26 \%$ and $55 \%$ respectively. At cardiac catheterisation, both right and left chamber pressures were within normal range. No " $a$ " waves were present on the right atrial and left ventricular pressure tracings. The right ventricle was globally enlarged and hypokinetic without obvious left ventricular abnormality. The coronary arteries were normal with a dominant left system. The patient was treated with mexiletine ( $100 \mathrm{mg}$ four times daily) and remained symptom free with frequent ventricular extrasystoles until his transfer to the Tel-Aviv Medical Center.

\section{ELECTROPHYSIOLOGICAL STUDY}

This study was performed by standard techniques while the patient was on mexiletine. Attempts to catheterise the coronary sinus to record left atrial activity were unsuccessful. A junctional escape rhythm with a cycle length of $1540-1660 \mathrm{~ms}$ was present with an $\mathrm{HV}$ interval of $50 \mathrm{~ms}$. No electrical activity could be recorded at multiple right atrial sites. Atrial pacing at these sites, using stimuli of up 
(a)

(b)

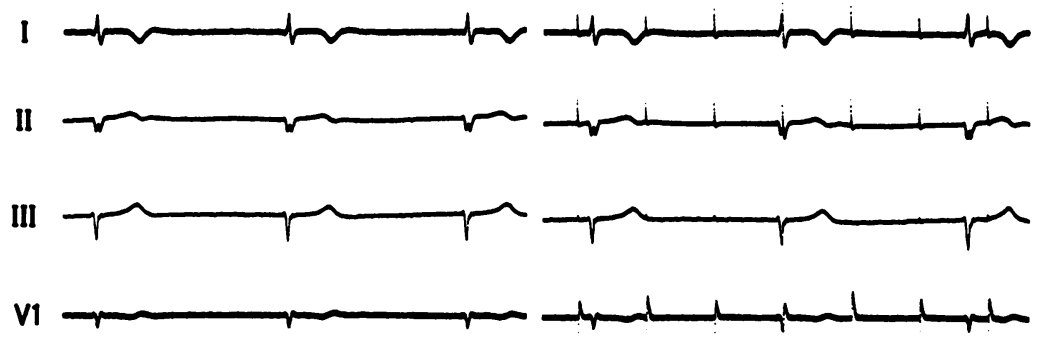

AVJ

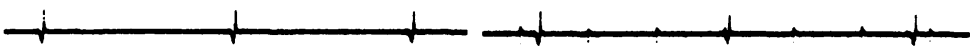

HRA

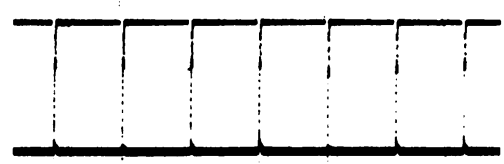

LRA

Fig 1 Electrocardiograms from leads $I, I I, I I I, V I$ and intracardiac electrograms from the atrioventricular junction ( $A V J)$, high right atrium (HRA), and low right atrium ( $L R A$ ) showing atrial paralysis. (a) No electrical activity was visible in the $H R A$ and LRA electrograms. (b) Pacing from the HRA with a $20 \mathrm{~mA}$ stimulus did not capture the atrium.

(a)

(b)

(c)

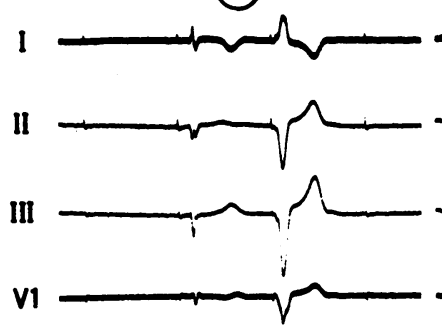<smiles>CCCCCC(CC)(CCCCC)C(C)(C)CC</smiles>

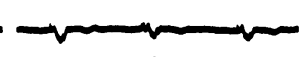<smiles>CCC(C)CCC(C)CCC(C)CC</smiles><smiles>CCCCC1CCCC(CC)C1CCC(C)CC</smiles><smiles>CCCCC(C)CCC(C)CCC</smiles><smiles>CCC(C)CCC(C)CC(C)C</smiles>
$\rightarrow \sim r$

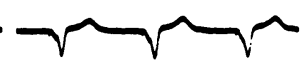

RVA
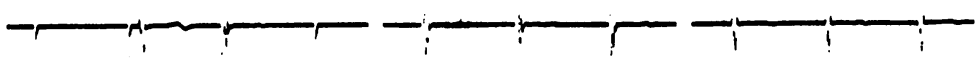

RVOT

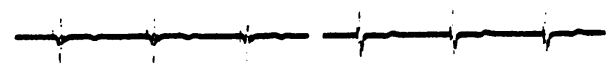

AVJ

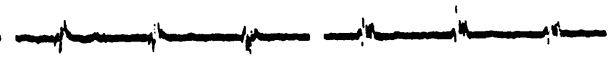

Fig 2 Electrocardiograms showing hypoexcitability of the right ventricular apex (RVA). (a) Pacing the $R V A$ with a $10 \mathrm{~mA}$ stimulus resulted in intermittent ventricular capture. (b) Pacing the RVA with a $20 \mathrm{~mA}$ stimulus produced permanent ventricular capture. (c) Consistent ventricular pacing was achieved from the right ventricular outflow tract with a $2 \mathrm{~mA}$ stimulus. 
to $20 \mathrm{~mA}$ in intensity failed to capture the atrium (fig 1). The amplitudes of the right ventricular electrograms were markedly reduced. Pacing at the apical, inferior, and anterior areas of the right ventricle was consistently effective only when stimuli of at least $15 \mathrm{~mA}$ were used. In contrast, pacing at the right ventricular outflow tract could be achieved with stimuli as low as $0.6 \mathrm{~mA}$ (fig 2). Sustained ventricular tachycardia (cycle length $180-220 \mathrm{~ms}$ ) with left bundle branch block configuration was induced when two extrastimuli were delivered to the right ventricular outflow tract. This tachycardia was poorly tolerated and required immediate cardioversion for termination. Addition of quinidine ( $500 \mathrm{mg}$ three times daily) to the continuing mexiletine treatment did not prevent induction of sustained ventricular tachycardia.

FOLLOW UP

Quinidine was discontinued because of considerable QT prolongation. The patient refused the offer of an implantable automatic defibrillator and permanent pacemaker. Two and a half years after discharge he was symptom free on mexiletine alone while showing permanent junctional escape rhythm of about 40 beats/min with frequent and multifocal extrasystoles.

\section{Discussion}

Our patient has several of the features that are typical of arrhythmogenic right ventricular dysplasia. ${ }^{1}$ In addition, he showed some unusual manifestations of this cardiomyopathy: (a) ventricular fibrillation as the presenting symptom; (b) atrial paralysis, and (c) hypoexcitable right ventricle.

Although ventricular fibrillation has been occasionally noted in arrhythmogenic right ventricular dysplasia, ${ }^{2}$ its occurrence as the presenting symptom of this cardiomyopathy in an apparently healthy patient has been reported in only one instance. ${ }^{3}$ This suggests that right ventricular dysplasia should be considered as a possible, although most probably rare, cause of sudden cardiac death.

The diagnosis of atrial paralysis (also called "atrial standstill") was based on the following findings: absence of $\mathbf{P}$ waves on standard and intracardiac electrograms, lack of atrial excitability, and absence of atrial contraction and atrial pressure changes. ${ }^{4}$ As far as we know this is the first report of atrial paraly- sis associated with right ventricular dysplasia. Because both are rare conditions their association may not have been fortuitous.

The considerable disturbances of right ventricular excitability that we found in our patient have been reported in a patient with Uhl's disease, ${ }^{5}$ which is assumed to be an extreme form of right ventricular dysplasia. ${ }^{6}$ Although severe forms of right ventricular dysplasia might be expected to produce hypoexcitability of the right ventricle, we do not know of similar findings being reported during electrophysiological studies in patients with this cardiomyopathy.

The association of atrial paralysis with hypoexcitability of several areas of the right ventricle including the apex has important clinical implications, especially when pacemaker implantation is being considered. Endocardial pacing from either the right atrium or the right ventricular apex will not be effective in such patients. Although pacing from the normally excitable right ventricular outflow tract with active fixation electrodes may be considered, the possibility that the progression of the disease will later impair this area ${ }^{1}$ suggests that epicardial pacing (ideally from the left ventricle) will be required.

We thank Dr Walter Markiewicz (Rambam Medical Center, Haifa) for performing the cardiac catheterisation of this patient.

\section{References}

1 Marcus FI, Fontaine GH, Guiraudon G, et al. Right ventricular dysplasia: a report of 24 adult cases. Circulation 1982;65:384-98.

2 Rowland E, McKenna WJ, Sugrue D, Barclay R, Foale RA, Krikler DM. Ventricular tachycardia of left bundle branch block configuration in patients with isolated right ventricular dilatation. Clinical and electrophysiological features. $B r$ Heart $J$ 1984;51: 15-24.

3 Olsson SB, Edvardsson N, Emanuelsson H, Enestrom S. A case of arrhythmogenic right ventricular dysplasia with ventricular fibrillation. Clin Cardiol 1982; 5:591-6.

4 Combs DT, Bellaci HF, Shively HH, Gregoratos G. Persistent atrial standstill. Am J Med 1974;56:231-6.

5 Bharati S, Ciraulo DA, Bilitch M, Rosen KM, Lev M. Inexcitable right ventricle and bilateral bundle branch block in Uhl's disease. Circulation 1978;57: 636-44.

6 Fontaine G, Guiraudon G, Frank R, et al. Dysplasie ventriculaire droite arythmogène et maladie de Uhl. Arch Mal Coeur 1982;72:361-71. 